\title{
Intrinsic rewards and work engagement in the South African retail industry
}

\begin{tabular}{|c|c|}
\hline $\begin{array}{l}\text { Authors: } \\
\text { Sara Jacobs }{ }^{1} \\
\text { Michelle Rena } \\
\text { Robin J. Snelga }\end{array}$ & \\
\hline \multicolumn{2}{|c|}{$\begin{array}{l}\text { Affiliations: } \\
{ }^{1} \text { Department of Industrial } \\
\text { and Organisational } \\
\text { Psychology, Nelson Mandela } \\
\text { Metropolitan University, } \\
\text { South Africa }\end{array}$} \\
\hline \multicolumn{2}{|c|}{$\begin{array}{l}\text { Correspondence to: } \\
\text { Michelle Renard }\end{array}$} \\
\hline \multicolumn{2}{|c|}{$\begin{array}{l}\text { Email: } \\
\text { michelle.renard@nmmu. } \\
\text { ac.za }\end{array}$} \\
\hline \multicolumn{2}{|c|}{$\begin{array}{l}\text { Postal address: } \\
\text { PO Box } 77000 \text {, Port Elizabeth } \\
6031 \text {, South Africa }\end{array}$} \\
\hline \multicolumn{2}{|c|}{$\begin{array}{l}\text { Dates: } \\
\text { Received: } 23 \text { Jan. } 2014 \\
\text { Accepted: } 17 \text { June } 2014 \\
\text { Published: } 05 \text { Nov. } 2014\end{array}$} \\
\hline \multicolumn{2}{|c|}{$\begin{array}{l}\text { How to cite this article: } \\
\text { Jacobs, S., Renard, M., } \\
\text { \& Snelgar, R.J. (2014). } \\
\text { Intrinsic rewards and work } \\
\text { engagement in the South } \\
\text { African retail industry. } \\
\text { SA Journal of Industrial } \\
\text { Psychology/SA Tydskrif vir } \\
\text { Bedryfsielkunde, 40(2), Art. } \\
\text { \#1195, } 13 \text { pages. http:// } \\
\text { dx.doi.org/10.4102/sajip. } \\
\text { v40i2.1195 }\end{array}$} \\
\hline \multicolumn{2}{|c|}{$\begin{array}{l}\text { Copyright: } \\
\text { (C) 2014. The Authors. } \\
\text { Licensee: AOSIS } \\
\text { OpenJournals. This work } \\
\text { is licensed under the } \\
\text { Creative Commons } \\
\text { Attribution License. }\end{array}$} \\
\hline \multicolumn{2}{|l|}{ Read online: } \\
\hline 口ifta & $\begin{array}{l}\text { Scan this QR } \\
\text { code with your } \\
\text { smart phone or } \\
\text { mobile device } \\
\text { to read online. }\end{array}$ \\
\hline
\end{tabular}

Orientation: There is a lack of South African research relating to the provision of intrinsic rewards to retail employees.

Research purpose: The purpose of this research was to determine whether there is a relationship between intrinsic rewards and work engagement in the South African retail industry. Furthermore, it sought to validate an instrument to measure intrinsic rewards within the South African context.

Motivation for the study: There is currently a paucity of research exploring intrinsic rewards, specifically their importance for work engagement. Furthermore, there is a lack of instruments validated in South Africa that can be used to measure intrinsic rewards.

Research approach, design and method: This quantitative study was conducted using a cross-sectional design and non-probability sampling of 181 employees from a South African retail organisation. The questionnaire included a demographic section, the Utrecht Work Engagement Scale and the Work Engagement Profile.

Main findings: Statistically significant, positive relationships were found between all subscales of the two instruments. There were significant differences in the means for intrinsic rewards and work engagement for gender and age. Notably, the exploratory factor analysis for both instruments did not support the factor structure indicated in the literature.

Practical/managerial implications: South African retail organisations should create work environments that provide intrinsic rewards as part of their reward package, to encourage work engagement.

Contribution/value-add: These findings add to the current body of literature regarding intrinsic rewards and work engagement and provide insight into variables that promote work engagement within the South African retail context.

\section{Introduction}

Traditionally, organisations have used money, benefits and other extrinsic rewards to attract, retain, motivate and engage employees, believing that properly administered extrinsic rewards systems were the panacea for all employee issues (Allen \& Helms, 2001). Extrinsic rewards are typically financial in nature and are external to the work itself, including any tangible reward provided to employees (Thomas, 2009a). Unlike extrinsic rewards, intrinsic rewards are intangible and fundamentally inherent in a job (Taylor, 2008).

At the beginning of the 20th century, work often consisted of repetitive, highly prescribed routine tasks, requiring rule compliance (Pink, 2009; Thomas, 2009a). The use of extrinsic rewards was effective in motivating behaviours relevant to such tasks (Pink, 2009). However, there have been many important economic, business and social developments that have changed the nature of work and the working environment. Thus, whilst extrinsic rewards such as base pay have to date been cited as the most preferred rewards by South African employees (Snelgar, Renard \& Venter, 2013), the aforementioned developments require re-evaluating the rewards provided to employees.

With many repetitive manufacturing jobs being sent overseas, there is now greater importance being placed on knowledge and service-based industries (Armstrong \& Brown, 2009). Coupled with the changing type of work, tough economic times and the increasingly competitive nature of the global marketplace, organisations have begun re-examining traditional reward methods. Furthermore, not only have employees' expectations of their employers changed, but younger generations of employees are particularly likely to want purpose, meaning and development opportunities in their jobs, and are willing to leave if they do not receive these intrinsic rewards 
(Tsui \& Wu, 2005). Therefore, the use of and interest in intrinsic rewards is burgeoning, due to the positive workrelated impact of intrinsic rewards such as job satisfaction and emotional attachment (Nujjoo \& Meyer, 2012).

Organisations require employees to take initiative and responsibility, adapt to customer needs, provide creative solutions, share knowledge and work with other teams in the organisation to be successful (Cruz, Perez \& Cantero, 2009; Pink, 2009; Markova \& Ford, 2011). Jobs in the growing knowledge and service-based sectors often require high levels of employee innovation, knowledge and creativity (Markova \& Ford, 2011). These behaviours have been associated with work engagement (Towers Perrin, 2005; Purcell, Kinnie, Hutchinson, Rayton \& Swart, 2003; Thomas, 2009c).

In the retail industry, employee behaviours such as product knowledge, delivering on promises and actively listening to customers is what drives customer satisfaction (Evenson, 2007). For employees to behave in this manner, they must be mentally and emotionally engaged in their work and be willing to put in additional discretionary effort, all of which are features of work engagement (Gibbons, 2006). It is therefore not surprising that there has been growing interest into how to drive work engagement, including within the retail industry.

Moreover, with the flatter organisational structures that are characteristic of many modern organisations, there is now a greater need for employees to take initiative and be self-directing and flexible. With fewer middle managers, employees are to a certain extent required to self-manage their time and deliver independently on targets (Thomas, 2009c). This requires employees to be engaged in their work.

This current context has led to the re-evaluation of the use of purely financial means to motivate and engage employees, with increasing evidence showing that extrinsic rewards, on their own, are insufficient tools to motivate and engage staff (Pink, 2009; Thomas, 2009a).

\section{Research purpose and objectives}

There is a scarcity of research investigating the importance of intrinsic rewards in a South African context (Nujjoo \& Meyer, 2012). There have been no previous scientific studies focusing on the relationship between intrinsic rewards and work engagement within South Africa, as is evident from the literature review to follow. Coupled with this, to the authors' knowledge, there is no commercially available instrument to measure intrinsic rewards that has been validated in South Africa.

Work engagement is particularly important in the retail industry, in which an employee's level of work engagement has been found to be positively related to levels of customer satisfaction (Kenexa, 2012). It is important for organisations to understand what job characteristics are linked with work engagement to be able to increase the level of engagement of their employees.

Given the employee performance, attitudes and behaviours that organisations desire, ensuring that employees are engaged at work has become increasingly important, as mounting research links engaged employees to a multitude of positive employee and organisational benefits such as better psychological health, motivation and enthusiasm (Bakker \& Demerouti, 2009; Bakker, Schaufeli, Leiter \& Taris, 2008; Field \& Buitendach, 2011). There is therefore great impetus to better understand factors related to work engagement.

Based on the above, the primary purpose of this study is to address the gap in empirical research by investigating the relationship between intrinsic rewards and work engagement in the South African retail context. Additional aims include to investigate the impact of demographic variables such as age and gender on levels of intrinsic rewards and work engagement, as well as to determine with a level of statistical significance that the two measuring instruments employed in this study (namely, the Work Engagement Profile to measure intrinsic rewards and the Utrecht Work Engagement Scale to measure work engagement) are valid and reliable within the South African context.

In order to answer the research question, "What is the relationship between intrinsic rewards and work engagement in the South African retail industry?" - this article will provide a brief literature review outlining intrinsic rewards and work engagement, followed by the research design for this study. Thereafter, a discussion of the results will be provided, which will address the study's purpose and objectives.

\section{Literature review Intrinsic rewards}

Intrinsic rewards are psychological rewards or positive and emotionally rewarding work-related experiences that individuals gain from their work and work environment (Thomas, 2009a). Unlike extrinsic rewards, they are intangible, yet are fundamentally inherent in a job (Taylor, 2008). Since rewards motivate and reinforce behaviour, for the purpose of this study, any intrinsic factor that motivates within the work context has been interpreted as an intrinsic reward.

Intrinsic rewards have been conceptualised in slightly different ways by researchers. Pink (2009) specifies three key intrinsic rewards that drive motivation at work, namely autonomy, mastery and purpose. Houkes (2002) found a causal effect between task significance, autonomy, feedback, task variety and intrinsic work motivation. Therefore, work that provides an experience that is interesting, challenging, meaningful, enjoyable, fulfilling and has variety and advancement opportunities, as well as an environment that provides constructive feedback, is intrinsically rewarding. 
This is because it enables employees to feel competent, responsible and autonomous, which increases intrinsic work motivation for employees (Amabile, Hill, Hennessey \& Tighe, 1994; Bitzer, Schrettl \& Scroder, 2007; Herzberg, 1966; Shamir, 1991; Marchington \& Wilkinson, 2008; Thomas, 2009a). Confirmed by Hackman and Lawler's (1971) Job Characteristics Theory, work and a working environment that can produce these emotional outcomes described above promote personal satisfaction and individual growth.

For the purposes of this study, Thomas's (2009a) intrinsic rewards will be focused on. Thomas specifies four types of intrinsic rewards gained from work, which provide positive emotional energy and result in motivation and positive feelings. These intrinsic rewards are a sense of meaningfulness, choice, competence and progress.

Meaningfulness involves the feeling that one's job is worthwhile and has a purpose that is part of a bigger picture (Thomas, 2009b). It includes employees knowing why they do what they do and knowing that their daily tasks contribute in some way to a larger whole, that is, that they are significant to the success of the organisation (Pink, 2009). Working towards a worthwhile purpose is rewarding and satisfying for employees and can sustain motivation over the long-term (Thomas, 2009c).

Choice is similar to the intrinsic reward of 'autonomy' described by other authors (Amabile et al., 1994; Pink, 2009). It includes the ability to choose one's own activities and methods of performing these activities and empowers employees to be self-directing, independent and responsible for their work outcomes (Thomas, 2009c). Allowing employees to be autonomous to select their own methods for accomplishing a task enables them to feel personally responsible for the quality of their activities and subsequent outcomes, such as the service received by the customer (Thomas, 2009c).

Competence at work involves employees feeling capable of handling their work tasks and performing in a way that meets or exceeds their personal standards of achievement (Deci \& Ryan, 1985; Thomas, 2009a). It can be seen as similar to the concept of 'mastery' as defined by Pink (2009), which emphasises employees continuously learning and putting in effort in order to improve at something that matters.

Finally, a sense of progress involves feeling that one's work is moving in the desired direction and accomplishing the desired or required outcomes (Thomas, 2009a). Particularly if the goal is meaningful, progress provides enthusiasm and positive feelings, creating motivation to continue (Thomas, 2009c).

Intrinsic rewards have been linked to many important outcomes for organisations. For example, Thomas (2009a) has found the abovementioned four intrinsic rewards to be strongly correlated to job satisfaction and professional development (Sutz, 1991, cited in Thomas, 2009b; Thomas
\& Tymon, 1994). Intrinsic rewards have been shown to be positively correlated with creativity (and extrinsic rewards negatively correlated with creativity) (Amabile et al., 1994). Employees who experience high levels of intrinsic rewards report higher levels of job satisfaction, lower stress, strong feelings of well-being and intrinsic motivation, as well as increased professional development (Ryan \& Deci, 2000; Sutz, 1991, in Thomas, 2009b; Thomas \& Tymon, 1994).

Furthermore, in the South African context intrinsic rewards have been linked to affective commitment and intrinsic motivation (Nujjoo \& Meyer, 2012). Pink (2009) explains that intrinsic rewards can create sustainable motivation over the long-term, because the need for competence or mastery of tasks is a long-term process. Furthermore, Pink argues that the use of intrinsic rewards reduces the requirement for supervision and middle management, because employees are intrinsically motivated and therefore self-directing.

\section{Work engagement}

Work engagement is part of the positive psychology movement, focusing on optimal functioning, well-being, enthusiasm and health at work (Schaufeli \& Bakker, 2003). Gibbons (2006) defines work engagement as the increased emotional and intellectual connection that employees have for their job, organisation or co-workers, which leads to increased discretionary effort in their work. The key attitudinal and behavioural components for work engagement definitions include commitment, enthusiasm towards work, dedication, loyalty, directed effort, involvement in one's job and satisfaction (Gallup, 2012; Macey \& Schneider, 2008; Towers Perrin, 2005).

Kahn (1990) states that employees are engaged with their work when they identify with their roles, and express themselves through their roles physically, emotionally and cognitively. Work engagement has also been defined as the antithesis of burnout (Maslach \& Leiter, 1997). However, Schaufeli, Salanova, Gonza'lez-Roma and Bakker (2002) argue that burnout and work engagement are distinct and should be assessed separately and independently of one another.

For the purpose of this research, work engagement will be defined based on Schaufeli et al.'s (2002) conception of work engagement: a positive work-related state of mind, defined by three dimensions, namely vigour, dedication and absorption. Vigour includes mental resilience, persistence when confronted with difficulties at work, pervasive positive feelings, energy and enthusiasm towards work (Bakker et al., 2008; Schaufeli \& Bakker, 2003). Dedication is characterised by enthusiasm, pride, persistence and being actively involved in one's work, including feeling challenged by one's job (Bakker et al., 2008). Absorption is when individuals are concentrating so fully and are so engrossed in their work that time passes without being noticed (Bakker et al., 2008).

Research on work engagement has found a positive relationship with the ability to cope in stressful situations, 
higher job enthusiasm, job satisfaction, happiness at work and organisational commitment (Bakker et al., 2008; Bakker \& Demerouti, 2009; Field \& Buitendach, 2011). At an organisational level, work engagement has been strongly correlated with positive outcomes such as lower absenteeism, higher retention, fewer safety incidents, increased productivity, higher company profits and increased customer loyalty and satisfaction (Bakker \& Demerouti, 2009; Gallup, 2012; Harter, Schmidt \& Hayes, 2002; Harter, Schmidt, Killham \& Asplund, 2006; Schaufeli \& Bakker, 2003).

\section{Relationship between intrinsic rewards and work engagement}

Organisations have realised that 'throwing money' at employees may have little effect on work engagement, and thus have now begun focusing on ways to enable intrinsic rewards (Towers Perrin, 2005). For this reason, there are a range of studies that have related intrinsic rewards and sources of intrinsic rewards to work engagement. For example, sources of intrinsic rewards such as job challenge, inclusion in decision-making and development opportunities have been found to be positively related to work engagement (Gibbons, 2006; Purcell et al., 2003). According to the job-demand resources model, job autonomy, task variety, positive performance feedback and social support gained from work are strongly positively related to work engagement (Bakker \& Demerouti, 2007). Rothmann and Rothmann (2010) validated this model in the South African context. Most of these studies are cross-sectional in design and therefore causation cannot be established.

Shernoff, Csikszentmihalyi, Schneider and Shernoff (2003) found that when students experienced tasks to be sufficiently challenging and had the appropriate skills to competently achieve the tasks, they had higher levels of engagement. This highlights that competence is related to higher levels of work engagement. Organisational cultures that restrict autonomy and empowerment have been found to be related to lower job satisfaction and work engagement (Nantha, 2013).

Kahn (1990) argues that if a task is meaningful to employees, then they will be more motivated to be engaged in their work. Empirical research supports this argument, finding that meaningfulness of work is a strong predictor of work engagement in the South African context (Olivier \& Rothmann, 2007; Rothmann \& Rothmann, 2010).

\section{Research design \\ Research approach}

This research falls within the paradigm of positive psychology (see Seligman \& Csikszentmihalyi, 2000), focusing on positive organisational attitudes in the South African work context. The study used a quantitative research method, having utilised questionnaires to collect data. A pilot study was initially conducted as part of the empirical research, followed by a final study based on the pilot study results. A cross-sectional design, which involves drawing a sample from the target population at a single point in time (Babbie, 2013), was utilised for both the pilot study and final study.

The purpose of the pilot study $(n=33)$ was to determine whether the two instruments, the Work Engagement Profile (WEP) and the Utrecht Work Engagement Scale (UWES), maintained reliability within the South African context. This was necessary because the WEP has not previously been utilised in South Africa. Based on Cronbach's alpha analysis, each subscale and the overall scales of the WEP and UWES had sufficient internal reliability and sufficient inter-item reliability levels. The Cronbach's alphas for the pilot study were 0.95 and 0.90 respectively. Therefore, both instruments were determined to be reliable for use in the final study, with no need to remove or edit any items. These tables were excluded from this article due to space constraints. The method and results presented thus relate only to the final study.

\section{Research method \\ Research participants}

The target population for this study was employees working within the South African retail industry. The sample was drawn from a single South African retail organisation, headquartered in Port Elizabeth, South Africa. Nonprobability sampling in the form of purposive sampling was used to collect data. Purposive sampling involves selecting a sample based on the target population and the nature of the research aims (Babbie, 2013).

Whilst 323 questionnaires were distributed to employees, a total of 208 completed questionnaires were returned. This reflects a response rate of $64.4 \%$. Of these 208 returned questionnaires, 13 were incomplete and were therefore excluded. In addition, Malhotra (2010) explains that data that is logically inconsistent may be regarded as unsatisfactory and therefore should be excluded. Item response bias, where respondents give inaccurate information, may also bias the results and should be excluded (Malhotra, 2010). In total, 14 respondents ticked only one answer (for example, strongly agree) for every item in their questionnaires. For the reasons mentioned above, these were regarded as biased and inconsistent and were thus excluded. The total number of questionnaires used for analysis was therefore 181 . This represents responses from $56 \%$ of the sample.

Characteristics of the sample: Table 1 displays the biographical characteristics of the respondents. This sample was comprised of $37(20.4 \%)$ men and 144 (79.6\%) women. The largest proportion of the sample was aged 28 to 37 years (40.3\%), followed by 18 to 27 years (30.9\%). Table 1 also shows that $37.0 \%$ of the respondents were mixed race, $36.5 \%$ were black and $25.4 \%$ were white. In terms of occupational groups, the factory and warehouse group made up the largest proportion of the sample $(52.5 \%)$, followed by employees working directly with customers (32.0\%) and head office employees (15.5\%). 


\section{Measuring instruments}

The composite questionnaire used for this study was a fixed answer questionnaire, requiring the respondents to select from a series of pre-determined answers (Malhotra, 2010). It consisted of a biographical data section and two measuring instruments, namely the WEP and UWES.

The Work Engagement Profile (WEP): The WEP is a global, commercially available instrument used to measure intrinsic rewards in organisations. It is owned by the American company CPP (Thomas, 2009b). Whilst this instrument is usually purchased for use, CPP granted permission to the authors to use this instrument for academic research purposes.

This 24-item self-report questionnaire is comprised of four subscales, which measure the extent to which the four types of intrinsic rewards explained in the literature review (namely meaningfulness, competence, choice and progress) are experienced within a respondent's work. Each subscale contains six items, measured using a seven-point Likert scale. Respondents are required to choose their level of agreement or disagreement for each item from the predetermined categories, ranging from 0 (strongly disagree) to 6 (strongly agree). The WEP was selected because it is one of the only available previously validated instruments found by the authors to measure levels of intrinsic rewards in an organisational setting.

For this study, certain words on several items were changed or substituted in the WEP by the authors, to ensure that the items would be interpretable within the South African context. Permission was granted from CPP to make these changes, and a legal contract was drawn up between the authors and CPP in this regard.

The Utrecht Work Engagement Scale (UWES): The UWES was used to measure work engagement in the sample. The UWES was originally developed as a 24-item questionnaire to measure these dimensions, mostly consisting of positively

TABLE 1: Characteristics of respondents $(n=181)$.

\begin{tabular}{|c|c|c|c|}
\hline Variable & Item & $f$ & $\%$ \\
\hline \multirow[t]{2}{*}{ Gender } & Male & 37 & 20.4 \\
\hline & Female & 144 & 79.6 \\
\hline \multirow[t]{5}{*}{ Age } & $18-27$ & 56 & 30.9 \\
\hline & $28-37$ & 73 & 40.3 \\
\hline & $38-47$ & 27 & 14.9 \\
\hline & $48-57$ & 16 & 8.8 \\
\hline & $58+$ & 9 & 5.0 \\
\hline \multirow[t]{5}{*}{ Racial group } & White & 46 & 25.4 \\
\hline & Black & 66 & 36.5 \\
\hline & Indian & 1 & 0.6 \\
\hline & Mixed-race & 67 & 37.0 \\
\hline & Other & 1 & 0.6 \\
\hline \multirow{3}{*}{$\begin{array}{l}\text { Occupational } \\
\text { group }\end{array}$} & Mainly directly with customer & 58 & 32.0 \\
\hline & $\begin{array}{l}\text { Working only occasionally customers, mainly } \\
\text { head office }\end{array}$ & 28 & 15.5 \\
\hline & Factory or warehouse & 95 & 52.5 \\
\hline
\end{tabular}

$f$, frequency. rephrased items from Maslach's Burnout Inventory (Maslach, Jackson \& Leiter, 1996). This instrument was validated on two different samples, during which 17 items were determined to be sound (Schaufeli et al., 2002). The UWES uses a seven-point Likert-scale, on which respondents select how often they have each feeling at work, ranging from 0 (Never) to 6 (Always).

The UWES is composed of three subscales, namely vigour (six items), dedication (five items) and absorption (six items). These measure the three dimensions of work engagement explained in the literature review.

Strong internal consistency has been found for the UWES both internationally and in the South African context (see for example, Coetzee \& De Villiers, 2010; Rothmann \& Rothmann, 2010; Schaufeli \& Bakker, 2003; Storm \& Rothmann, 2003). Storm and Rothmann (2003) found that the UWES can be used to measure work engagement in South Africa, as there is no uniform or non-uniform bias between racial groups.

\section{Research procedure and ethical considerations}

A paper-and-pen method was used for this study. The introduction to the questionnaire stated the purpose of the research, instructions for completing the questionnaire and assurances of confidentiality and anonymity. The collection procedure varied slightly depending on whether the respondent was at head office, factory and warehouse or the retail stores.

Head office, factory and warehouse employees: The authors handed out questionnaires to every member of staff and left a sealed questionnaire collection box at reception for completed questionnaires to be dropped into.

Retail employees: The organisation's regional retail managers assisted with the data collection by handing out questionnaires to all employees at every store. A sealed questionnaire collection box was left in each store, into which completed questionnaires could be deposited. All boxes from around SA were then delivered directly to the authors upon completion of the data collection phase.

Ethical considerations: To ensure that the research was conducted in an ethical manner, permission to conduct the study was obtained from the owners and directors of the retail organisation prior to the beginning of the study. An email was then sent out to all employees of the organisation by the head of human resources, outlining the purpose and procedure of the research and requesting support from the organisation's employees. Managers with access to computers were asked to pass this information on to all employees without computer access. Whilst all employees were requested to take part in the study, participation was purely voluntary and no employees were forced or coerced to take part. Consent was assumed by the act of 
filling in the questionnaire and returning it. Confidentiality and anonymity was ensured for all participants and no employee names or individual identifiers appeared on the questionnaires. All completed questionnaires were dropped into the sealed communal collection boxes mentioned above, in order to maximise the perception of anonymity for the participants. Finally, no information about individual respondents was given to the organisation once the data had been analysed.

\section{Statistical analysis}

To complete the statistical analysis, two programs were utilised, namely Microsoft Excel and Statistica (version 11), a statistics and analysis software package. Descriptive statistics were utilised to describe the data, including the mean, minimum, maximum and standard deviation. Cronbach's alpha coefficients were calculated for each subscale in the WEP and UWES to determine the internal consistency between each item and evaluate the reliability of each instrument.

Confirmatory factor analysis was performed to determine the underlying factor structure of the WEP and UWES for the South African sample in this study. Pearson product moment correlations were utilised to ascertain the strength of the relationships between each factor within the WEP and UWES (Malhotra, 2010). A coefficient of 0.30 or above was used as a cut-off to represent practically significant correlations (Hair, Black, Babin \& Anderson, 2010).

Analysis of variance (ANOVA) was used to determine whether there were statistically significant differences across demographic variables with more than two levels (age, race and occupational group). T-tests were used to determine statistical differences between genders. Furthermore, post-hoc Tukey tests were performed to determine whether there were statistically significant differences for the WEP and UWES factors between demographic variables. Cohen's $d$ statistic, which reflects the effect size, was used to determine the practical significance of these results (Stommel \& Willis, 2004). The guidelines used for interpretation indicate that a small effect size occurs when $d$ is between 0.20 and 0.50 . A moderate effect size occurs when $d$ is between 0.50 and 0.80 and a large effect size occurs when $d$ is equal to or greater than 0.80 (Gravetter \& Wallnau, 2009).

\section{Results \\ Descriptive statistics and Cronbach's alpha coefficients}

Table 2 summarises the key descriptive statistics for the WEP and UWES by displaying the minimum, maximum, mean, standard deviation and Cronbach's alphas for the variables under study. It is evident that both measuring instruments have acceptable internal reliability as they are above 0.60 (Malhotra, 2010), with the reliability coefficient for the total WEP being 0.93 and for the total UWES being 0.82 . The authors note though that the Cronbach's alpha values for the WEP subscales in this study are slightly lower than those found by Burke (2004), Tymon (1994, in Thomas, 2009b), and Forest (2008, in Thomas 2009b). The same can be said for the UWES Cronbach's alpha values presented in Schaufeli and Bakker (2003), Storm and Rothmann (2003), and Coetzee and De Villiers (2010), as compared to this study.

\section{Confirmatory factor analysis}

Confirmatory factor analysis was conducted on the WEP and UWES ${ }^{1}$. For the WEP, four distinct factors accounted for $63.03 \%$ of the total variance. This is aligned with the fourfactor structure found by Thomas (2009b) in an American context. However, for the factor loading, some of the items did not load on the factors specified in the literature and test manual and there was no clear alternative factor structure (Stumpf, Doh \& Tymon, 2010; Burke, 2004; Thomas, 2009b; Thomas, Jansen \& Tymon, 1997).

For the UWES, the factor analysis suggested a four-factor structure. This finding is different to the three-factor structure previously found for the UWES (Schaufeli \& Bakker, 2003; Storm \& Rothmann, 2003). However, since the fourth factor only contributes $6.00 \%$ of the total variance, a three-factor structure may still be feasible. Similar to the WEP, the factor loading structure does not correspond with the structure found both internationally and in a South African context (Schaufeli \& Bakker, 2003; Storm \& Rothmann, 2003).

\section{Relationship between WEP and UWES factors}

Table 3 displays the Pearson product moment correlation coefficients that were calculated to determine the strength of the relationship between the factors in the WEP and UWES.

1.The tables depicting the results of the factor analysis were not included in this article due to their large sizes. They are however available from the authors upon request.

TABLE 2: Descriptive statistics for Work Engagement Profile (WEP) and Utrecht Work Engagement Scale (UWES).

\begin{tabular}{|c|c|c|c|c|c|c|}
\hline Instrument & Factor & Minimum & Maximum & $M$ & SD & Cronbach's alpha \\
\hline \multirow[t]{5}{*}{ WEP } & Meaningfulness & 11 & 42 & 36.39 & 4.98 & 0.82 \\
\hline & Choice & 6 & 42 & 31.06 & 8.22 & 0.86 \\
\hline & Competence & 13 & 42 & 36.92 & 4.78 & 0.82 \\
\hline & Progress & 12 & 42 & 36.26 & 5.23 & 0.82 \\
\hline & Total & - & - & - & - & 0.93 \\
\hline \multirow[t]{4}{*}{ UWES } & Vigour & 10 & 42 & 31.93 & 6.21 & 0.73 \\
\hline & Dedication & 5 & 35 & 28.29 & 6.30 & 0.82 \\
\hline & Absorption & 9 & 42 & 31.61 & 6.63 & 0.77 \\
\hline & Total & - & - & - & - & 0.82 \\
\hline
\end{tabular}

M, mean; SD, standard deviation. 
The relationships between all factors of the WEP and UWES are positive and practically significant $(r>0.30)$. Between the two instruments, absorption and choice had the lowest correlation $(r=0.46)$ and dedication and meaningfulness had the highest $(r=0.76)$. The strongest correlation amongst WEP factors is between meaningfulness and competence $(r=0.78)$ and the weakest relationship is between competence and choice $(r=0.49)$. For the UWES, vigour and dedication, and vigour and absorption, had the joint highest correlation at 0.75 , and dedication and absorption had the lowest correlation coefficient $(r=0.69)$.

\section{Impact of demographic variables}

Table 4 shows the ANOVA results for each factor, in terms of various demographic variables. Statistically significant relationships are represented by $p$-values less than 0.05 .

It is evident that for the WEP, there are statistically significant differences for meaningfulness across age and race, and for competence across age and race. In addition, for the UWES factors, there are statistically significant differences across age and race for vigour and absorption and across age for dedication. It should be noted that there are no statistically significant differences across the occupational groups; for this reason, further analysis was not conducted for this demographic variable.

Age and WEP/UWES factors: Post-hoc Tukey tests were used to determine significant differences for the factors meaningfulness and competence from the WEP and vigour, dedication and absorption from the UWES. Whilst the ANOVA in Table 4 identified both meaningfulness and competence as having statistically significant differences across age groups, the Tukey post-hoc test was not powerful enough to detect any pairwise differences for meaningfulness, at a significance level of less than 0.05 .

As seen in Table 5, however, for the factor competence, statistically significant differences occur between the 18-27 and 48-57 age groups, as well as the 28-37 and 48-57 age groups $(p<0.05)$. The Cohen's d scores above the diagonal line indicate practical significance, with the difference between $18-27$ and $48-57$ age groups having a moderate practical significance $(0.50<|d|<0.80)$. The difference between the 28-37 and 48-57 age groups has a Cohen's $d$ of 0.80 , indicating a large practical significance. Since the means generally increase as age groups increase, this suggests that competence may be positively related to age for this sample.

As seen in Table 6, there are statistically significant differences for the UWES factor vigour between the 18-27 age group and the age groups 38-47, 48-57 and 58+ $(p<0.05)$. In addition, there are statistically significant differences between the age group 28-37 and the age groups 38-47 and 58+. As evident from the Cohen's $d$ statistics above the diagonal line, all of these statistics have a large practical significance $(|d| \geq 0.80)$, except the difference between age groups $28-37$ and $38-47$, which has a moderate practical significance $(0.50<|d|<0.80)$. These results suggest a trend of significant differences between younger and older groups for vigour, with the means generally trending upwards as age increases.

For dedication, Table 7 indicates statistically significant differences between the age group 18-27 and the groups $48-57$ and 58+ years old $(p<0.05)$. According to Cohen's $d$ statistic, these differences are of moderate $(0.50<|d|<0.80)$ and large $(|d| \geq 0.80)$ practical significance respectively. In addition, the difference between the 28 to 37 and 58+ age group is also statistically significant. This suggests that older respondents (58+) have a higher mean score than younger respondents (28-37 years) and this difference has large practical significance $(|d| \geq 0.80)$. Since the means for dedication increase as age increases, this suggests a positive relationship between dedication and age.

From Table 8 it is evident that there is a statistically significant difference between respondents aged 18-27 and those aged 38-47 for the absorption factor of the UWES. Older respondents

TABLE 3: Pearson product moment correlation coefficients.

\begin{tabular}{|c|c|c|c|c|c|c|c|}
\hline Variable & 1 & 2 & 3 & 4 & 5 & 6 & 7 \\
\hline 1. Meaningfulness & - & - & - & - & - & - & - \\
\hline 2. Choice & $0.55 * *$ & - & - & - & - & - & - \\
\hline 3. Competence & $0.78 * *$ & $0.49^{*}$ & - & - & - & - & - \\
\hline 4. Progress & $0.73 * *$ & $0.57^{* *}$ & $0.73 * *$ & - & - & - & - \\
\hline 5. Vigour & $0.69 * *$ & $0.47^{*}$ & $0.63 * *$ & $0.58 * *$ & - & - & - \\
\hline 6. Dedication & $0.76 * *$ & $0.55^{* *}$ & $0.61 * *$ & $0.64 * *$ & $0.75 * *$ & - & - \\
\hline
\end{tabular}

$*, r>0.30=$ medium effect size (practically significant); ${ }^{* *}, r>0.50=$ large effect size (practically significant)

TABLE 4: Work Engagement Profile and Utrecht Work Engagement Scale factors according to demographic variables.

\begin{tabular}{|c|c|c|c|c|c|c|c|c|c|c|c|c|c|c|}
\hline \multirow[t]{3}{*}{ Demographic variables } & \multicolumn{8}{|c|}{ Work Engagement Profile } & \multicolumn{6}{|c|}{ Utrecht Work Engagement Scale } \\
\hline & \multicolumn{2}{|c|}{ Meaningfulness } & \multicolumn{2}{|c|}{ Choice } & \multicolumn{2}{|c|}{ Competence } & \multicolumn{2}{|c|}{ Progress } & \multicolumn{2}{|c|}{ Vigour } & \multicolumn{2}{|c|}{ Dedication } & \multicolumn{2}{|c|}{ Absorption } \\
\hline & $F$ & $p$ & $F$ & $p$ & $F$ & $p$ & $F$ & $p$ & $F$ & $p$ & $F$ & $p$ & $F$ & $p$ \\
\hline Age & 3.49 & $0.009 *$ & 0.67 & 0.614 & 3.98 & $0.004 *$ & 1.59 & 0.179 & 8.41 & $0.000 *$ & 5.02 & $0.001 *$ & 4.63 & $0.001 *$ \\
\hline Race & 3.10 & $0.048^{*}$ & 0.16 & 0.852 & 3.22 & $0.042 *$ & 0.89 & 0.411 & 3.62 & $0.029 *$ & 0.58 & 0.564 & 3.17 & $0.044 *$ \\
\hline Occupational group & 0.65 & 0.522 & 1.68 & 0.189 & 0.58 & 0.558 & 1.61 & 0.202 & 1.11 & 0.330 & 1.17 & 0.314 & 1.31 & 0.274 \\
\hline
\end{tabular}

$*, p<0.05=$ statistically significant. 
(38-47) have a higher mean than younger respondents (18-27) for absorption and this difference has a moderate practical significance $(0.50<|d|<0.80)$. In addition, the difference between respondents aged 28-37 and 38-47 is statistically significant, again with a moderate practical significance. From Table 8 it can be seen that the means for absorption generally increase as the age groups increase.
Gender and WEP/UWES factors: Two-sample independent t-tests were used to identify gender differences for scores on each of the factors. The only significant difference for gender was on the competence factor (see Table 9), with female respondents reporting higher levels of competence than male respondents $(p<0.05)$. This difference is of small practical significance $(0.20<|d|<0.50)$.

TABLE 5: Tukey tests and Cohen's $d$ for competence, according to age.

\begin{tabular}{|c|c|c|c|c|c|}
\hline Age & $\begin{array}{l}18-27 \\
(\mathrm{M}=36.11)\end{array}$ & $\begin{array}{l}28-37 \\
(\mathrm{M}=36.10)\end{array}$ & $\begin{array}{l}38-47 \\
(\mathrm{M}=38.15)\end{array}$ & $\begin{array}{l}48-57 \\
(\mathrm{M}=39.81)\end{array}$ & $\begin{array}{l}58+ \\
(\mathrm{M}=39.89)\end{array}$ \\
\hline $18-27$ & - & - & - & 0.78 & - \\
\hline $28-37$ & 1.000 & - & - & 0.80 & - \\
\hline $38-47$ & 0.326 & 0.281 & - & - & - \\
\hline $48-57$ & $0.038^{*}$ & $0.030^{*}$ & 0.785 & - & - \\
\hline $58+$ & 0.152 & 0.138 & 0.865 & 1.000 & - \\
\hline
\end{tabular}

$*, p<0.05=$ statistically significant.

Note: Above diagonal: Cohen's $d$; Below diagonal: Tukey tests.

TABLE 6: Tukey tests and Cohen's $d$ for vigour, according to age.

\begin{tabular}{|c|c|c|c|c|c|}
\hline Age & $\begin{array}{l}18-27 \\
(\mathrm{M}=29.48)\end{array}$ & $\begin{array}{l}28-37 \\
(\mathrm{M}=31.19)\end{array}$ & $\begin{array}{l}38-47 \\
(\mathrm{M}=35.48)\end{array}$ & $\begin{array}{l}48-57 \\
(\mathrm{M}=34.94)\end{array}$ & $\begin{array}{l}58+ \\
(\mathrm{M}=37.22)\end{array}$ \\
\hline $18-27$ & - & - & 1.09 & 0.96 & 1.37 \\
\hline $28-37$ & 0.450 & - & 0.72 & - & 0.99 \\
\hline $48-57$ & $0.007 *$ & 0.126 & 0.998 & - & - \\
\hline $58+$ & $0.002 *$ & $0.025 *$ & 0.935 & 0.876 & - \\
\hline
\end{tabular}

$*, p<0.05=$ statistically significant.

Note: Above diagonal: Cohen's $d$; Below diagonal: Tukey tests

TABLE 7: Tukey tests and Cohen's $d$ for dedication, according to age.

\begin{tabular}{|c|c|c|c|c|c|}
\hline Age & $\begin{array}{l}18-27 \\
M=26.86\end{array}$ & $\begin{array}{l}28-37 \\
M=27.22\end{array}$ & $\begin{array}{l}38-47 \\
M=30.56\end{array}$ & $\begin{array}{l}48-57 \\
M=31.69\end{array}$ & $\begin{array}{l}58+ \\
M=33.11\end{array}$ \\
\hline $18-27$ & - & - & - & 0.78 & 1.00 \\
\hline $28-37$ & 0.997 & - & - & - & 0.94 \\
\hline $48-57$ & $0.038 *$ & 0.057 & 0.976 & - & - \\
\hline $58+$ & $0.032 *$ & $0.045^{*}$ & 0.807 & 0.980 & - \\
\hline
\end{tabular}

$*, p<0.05=$ statistically significant.

Note: Above diagonal: Cohen's $d$; Below diagonal: Tukey tests

TABLE 8: Tukey tests and Cohen's $d$ for absorption, according to age.

\begin{tabular}{|c|c|c|c|c|c|}
\hline Age & $\begin{array}{l}18-27 \\
(\mathrm{M}=30.02)\end{array}$ & $\begin{array}{l}28-37 \\
(\mathrm{M}=30.58)\end{array}$ & $\begin{array}{l}38-47 \\
(\mathrm{M}=34.56)\end{array}$ & $\begin{array}{l}48-57 \\
(\mathrm{M}=34.50)\end{array}$ & $\begin{array}{l}58+ \\
(\mathrm{M}=35.89)\end{array}$ \\
\hline $18-27$ & - & - & 0.73 & - & - \\
\hline $28-37$ & 0.988 & - & 0.62 & - & - \\
\hline $48-57$ & 0.095 & 0.169 & 1.000 & - & - \\
\hline $58+$ & 0.077 & 0.127 & 0.983 & 0.985 & - \\
\hline
\end{tabular}

$*, p<0.05=$ statistically significant.

Note: Above diagonal: Cohen's $d$; Below diagonal: Tukey tests

TABLE 9: Results of the $t$-test for gender differences.

\begin{tabular}{|c|c|c|c|c|c|c|c|c|c|}
\hline \multirow[t]{2}{*}{ Constructs } & \multicolumn{2}{|c|}{ Mean } & \multicolumn{2}{|c|}{ SD } & \multirow{2}{*}{$\begin{array}{c}\text { Mean difference } \\
\text { (M-F) }\end{array}$} & \multirow[t]{2}{*}{$t$-value } & \multirow[t]{2}{*}{$d f$} & \multirow[t]{2}{*}{$p$} & \multirow[t]{2}{*}{ Cohen's $d$} \\
\hline & Male & Female & Male & Female & & & & & \\
\hline \multicolumn{10}{|c|}{ Work Engagement Profile } \\
\hline Meaningfulness & 35.70 & 36.57 & 6.05 & 4.67 & -0.867 & 0.94 & 179 & 0.346 & N/A \\
\hline Choice & 30.35 & 31.24 & 8.43 & 8.18 & -0.892 & 0.59 & 179 & 0.557 & $\mathrm{~N} / \mathrm{A}$ \\
\hline Competence & 35.49 & 37.29 & 5.86 & 4.40 & -1.805 & 2.07 & 179 & $0.040^{*}$ & 0.38 \\
\hline Progress & 35.08 & 36.56 & 5.65 & 5.09 & -1.481 & 1.54 & 179 & 0.125 & N/A \\
\hline \multicolumn{10}{|c|}{ Utrecht Work Engagement Scale } \\
\hline Vigour & 30.16 & 32.39 & 6.34 & 6.11 & -2.227 & 1.96 & 179 & 0.0513 & N/A \\
\hline Dedication & 26.57 & 28.74 & 7.22 & 5.99 & 2.169 & 1.88 & 179 & 0.0613 & $\mathrm{~N} / \mathrm{A}$ \\
\hline Absorption & 30.30 & 31.94 & 6.29 & 6.69 & -1.647 & 1.35 & 179 & 0.178 & N/A \\
\hline
\end{tabular}

$\mathrm{SD}$, standard deviation

$*, p<0.05=$ statistically significant. 


\section{Discussion Outline of the results}

The key research objectives of this study were to determine whether there was a relationship between intrinsic rewards and work engagement in the South African retail context, as well as to validate the WEP and UWES in the South African retail context and investigate the impact of demographic variables on these constructs. This research was conducted in a single retail organisation; therefore, generalisations from these results to the greater South Africa population are not appropriate.

\section{Relationship between intrinsic rewards and work engagement}

As shown in Table 3, all four WEP intrinsic rewards factors were found to be positively and significantly correlated to the three UWES work engagement factors. This indicates that individuals who are provided with high levels of intrinsic rewards at work typically experience high levels of work engagement, and are therefore more willing to exert additional effort as well as be more dedicated and actively involved in their work (Schaufeli \& Bakker, 2003). These findings confirm the results of previous research. For example, Shernoff et al. (2003) found that competence or mastery of a difficult task led to higher levels of engagement. Additionally, Rothmann and Rothmann (2010) confirmed the relevance of Schaufeli and Bakker's (2004) job-resources model within the South African context, discovering that job characteristics that provide intrinsic rewards including autonomy, growth opportunities, variety, learning opportunities and social support were strongly related to work engagement.

There are a number of different theories on how intrinsic rewards and work engagement are related; however, the nature and causality of this relationship have not yet been empirically tested in South Africa. For example, Thomas's (2009c) self-management model proposes that when employees have meaningful work, understand the purpose of their role, and have autonomy to make choices, then they can select the actions required to best achieve their goals. If they are achieving their goals, this reaffirms their competence and provides a sense of progress. Through this progress they gain positive emotional energy that is energising and rewarding, which therefore reinforces the benefits of being engaged with their work.

If employees are not achieving their goals, this provides feedback for the employees to re-evaluate and alter their behaviour. Thomas (2009c) highlights that this process requires employees to self-manage, in that they should initiate behaviour, actively evaluate their successes and make adjustments where necessary (Thomas, 2009b). This self-management model, which relates the gaining of intrinsic rewards to work engagement, has received support from studies in several countries (Forest, 2008, cited in Thomas, 2009b; Stumpf et al., 2010).
Rothmann and Rothmann's (2010) research supports the empirical findings of this study, which is that the strongest correlation between the intrinsic rewards and work engagement factors was between meaningfulness and dedication. This implies that individuals who find their work highly meaningful will likely demonstrate high levels of work dedication. Such an employee will strive to exceed goals, persevere with difficult tasks and be emotionally committed and thus engaged (Rothmann \& Rothmann, 2010). Kahn (1990), confirmed by Olivier and Rothmann (2007) in South Africa, found meaningfulness to be the strongest predictor of work engagement. Thomas (2009c) agrees with this, stating that when employees achieve their desired outcomes and contribute to a meaningful purpose, this provides positive emotional energy, which is motivating and engaging.

\section{Impact of age on intrinsic rewards and work engagement}

Table 4 shows that statistically significant differences were found between age groups for the three UWES factors, namely vigour, dedication and absorption, as well as the WEP factor of competence, which indicates that age is positively related to work engagement and competence. For competence, the positive relationship with age is clear: with age comes experience and sufficient time to master one's skills and overall job competence.

The relationship between age and work engagement aligns with international research that has found that older employees have higher levels of work engagement than younger employees (Schaufeli \& Bakker, 2003; Schaufeli, Bakker \& Salanova, 2006; Simpson, 2009; James, McKechnie \& Swanberg, 2011). The explanation for this relationship is not clear though. James et al. (2011) suggest that older workers may have different expectations of work and may therefore respond differently from younger employees to the same working conditions. These authors suggest that older workers are more concerned with job security and company loyalty than younger workers and are therefore more likely to persevere at their job and stay engaged than younger workers. Lancaster and Stillman (2002) propose that younger employees demand greater challenges and meaning in their work and are not as patient as older workers. Therefore, for the same level of work and working conditions, older employees may be more accepting and therefore likely to be more engaged in their work than younger employees who are more likely to get frustrated and consequently detached.

\section{Impact of gender on intrinsic rewards and work engagement}

The only significant difference between genders was found for the competence factor of intrinsic rewards, with women reporting higher competence than men. This result, however, held small practical significance. Previous research suggests that men are significantly more likely to care about career advancement and monetary increases than women 
(Family and Work Institute, 2006). Whitehead and Kotze (2003) found that South African women's main motivation for working was related to intrinsic work factors, including giving their life meaning. Therefore, perhaps women are more interested in being competent at their current job than focusing on their next career move. As their current role is more important to them, women might rate themselves as being more competent in such roles. This assumption, however, is highly speculative.

\section{Factor analysis}

An interesting finding from this study was that the factor structure for the WEP and UWES did not support the factor structure outlined in the literature (Schaufeli et al., 2002; Thomas, 2009b). For the UWES, given that it has been validated in a wide variety of countries and industries, it is unlikely that this finding reflects a weakness in the construction of the UWES. For the WEP, given that the instrument has not been validated or used in South Africa before, it is not clear whether the factor structure findings point to potential construct and content validity issues or other factors specific to this study.

One potential reason for the factor structure findings may be that some respondents may not have understood the items in the same way as the samples in which the instruments were standardised. Both of these instruments were developed internationally and the WEP particularly has not been previously validated in South Africa. Many of the items in the WEP are Americanised and some of the terms may have been misunderstood by South Africans. Culture impacts heavily on perceptions and meaning of concepts, which brings about challenges in using instruments developed internationally (Hood, Hopson \& Frierson, 2005).

Another potential issue that may have contributed to this result is that the data was significantly skewed to the top end of the scale, with very few respondents answering 'strongly disagree' or 'disagree' on the lower end of the scale. The similarity of responses across all items in all subscales contributed to the lack of a clear factor structure. The authors speculate that this could be attributed to socially desirable responses on behalf of the respondents. Since this study was conducted in the workplace of the respondents, they may have been concerned with consequences of their results showing low levels of work engagement.

Even though the factor structures did not correspond to previous literature findings, the Cronbach's alpha coefficients for both the WEP and UWES were above the recommended criterion, indicating satisfactory reliability. For this reason, the results still provide beneficial insight into the retail sector within South Africa.

\section{Practical implications}

As previously discussed, intrinsic rewards are related to a wide range of positive outcomes that organisations may wish to encourage and sustain. These include greater organisational commitment, employee well-being and lower stress (Deci \& Ryan, 2000; Thomas \& Tymon, 1994). In addition, intrinsic rewards have been associated with the tendency to seek out challenges, improved creativity, as well as increased retention, recall and comprehension of information (Amabile et al., 1994; Ryan, Connell \& Plant, 1990; Ryan \& Deci, 2000). Retail organisations may greatly benefit from developing intrinsic reward interventions for their employees.

Due to the current economic climate, the skills shortages in South Africa and positive types of behaviour that organisations are trying to motivate, organisations need employees who are dedicated, willing to put in extra effort, good problem solvers, creative, energetic and emotionally resilient. In other words, organisations require engaged employees (Schaufeli \& Bakker, 2003). Thus both intrinsic rewards and work engagement are highly beneficial for the long-term success of an organisation.

The relationship found in this study between intrinsic rewards and work engagement provides greater insight into the organisational conditions that potentially facilitate higher levels of work engagement. This finding may have both theoretical and practical implications for the design of the work environment, human resource practices, reward practices and conditions required to optimise and increase motivation, engagement and well-being and, therefore, potentially improve company performance (Bakker \& Demerouti, 2007).

Whilst by definition intrinsic rewards are individual feelings and can therefore not be administered externally by an organisation, organisations can use techniques and create an environment that will provide employees with the opportunity to gain intrinsic rewards (Zenger \& Lazzarini, 2004). For example, a meaningful purpose for every organisation should be identified, explicitly stated and widely communicated (Thomas, 2009a). Employees must understand the purpose of their particular role within the wider organisation and feel as though they are contributing to this purpose (Thomas, 2009c). To increase autonomy and choice for employees, Marchington and Wilkinson (2008) advocate the redesigning of jobs by enlarging job responsibilities and providing greater discretion to make choices. Organisations must therefore ensure sufficient role clarity and inclusion in decision-making (Schaufeli \& Bakker, 2004).

Purcell et al. (2003) recommend instituting human resource policies and practices including learning and development opportunities, career advancement opportunities, job autonomy, challenging work, individual performance appraisals and work-life balance to foster and encourage intrinsic rewards and thus potentially work engagement. Non-financial reward interventions linked to intrinsic rewards can be established, such as the implementation of recognition programs. For these policies and practices to 
be effective, top management, human resource managers and line managers must work together to ensure effective implementation (Purcell et al., 2003).

\section{Limitations and recommendations}

Response bias impacts on the reliability and validity of results. It has already been mentioned that results may have been skewed due to social desirability, which is the tendency of respondents to provide responses that they believe are desired, whether they are true or not (Malhotra, 2010). As this research was conducted at the workplace of the respondents, it is possible that respondents wanted to portray themselves in a positive light. Acquiescence bias may also have been caused by respondents tending to agree with items by simply ticking 'strongly agree' or 'agree' to all items (Malhotra, 2010). Since there are no negatively phrased items on the WEP, respondents may have acquiesced and answered positively to all items, which may have biased the results.

Furthermore, the factor structure for both instruments did not align with previous research. Whilst the UWES has been proven through other studies to be valid and reliable in its current format in South Africa, these studies were conducted in industries different from the retail sector. Furthermore, the WEP was created and validated in America and uses numerous Americanised terms, which may have led to potential misunderstandings. However, in an attempt to increase the clarity of the questionnaire, the authors did provide brief explanations below each item for both the WEP and UWES.

Given the cross-sectional design of this study, no causal relationship can be established between intrinsic rewards and work engagement. Finally, given that this research was conducted in one South African retail organisation and the characteristics of respondents were not balanced in terms of demographic variables, the sample may limit generalisation to the wider population.

\section{Recommendations}

Future research should determine whether this study's findings can be replicated across other South African retail organisations and other industries. A more diverse sample of respondents would enable the sample to be more representative of the population. Moreover, an experimental intervention could be created in a South African organisation to determine whether there is a causal relationship between intrinsic rewards and work engagement and through what mechanisms intrinsic rewards impact on work engagement. In addition, to more fully understand the relationship between these two concepts, further investigations should explore potential mediating factors between intrinsic rewards and work engagement.

Future research could furthermore explore whether there are generational differences in attitudes towards work in a South African context, in order to understand how these differences impact on levels of work engagement. More research is also required to understand the differences and reasons behind gender and age differences pertaining to intrinsic rewards and work engagement in South African organisations.

Due to the fact that the WEP was not validated in this study, future research should be conducted to validate the WEP within the South African context. Additionally, given that South Africa has 11 official languages and English is a second language for many South Africans, research should investigate the possibility of translating the WEP and UWES instruments into other languages more appropriate for use in South Africa. To mitigate the potential limitation of response and acquiescence bias, negatively phrased items could be used in addition to positively phrased items.

\section{Conclusion}

Intrinsic rewards and work engagement are complex and nuanced concepts that are of great interest to researchers and organisations globally and the subject of much debate and investigation. This study focused specifically on understanding the relationship between these two constructs in the South African retail industry, as well as investigating any impact that demographic variables may have had.

A purposive non-probability sampling method was used for this quantitative study and a significant positive relationship was discovered between intrinsic rewards and work engagement. The results make several important contributions to the body of knowledge, providing greater insight into the use of intrinsic rewards to positively affect levels of work engagement in the South African retail industry. The results offer valuable information regarding the impact of demographic variables on intrinsic rewards and work engagement and indicate a positive relationship between age and certain intrinsic rewards and work engagement factors. The only gender difference found was on the intrinsic reward of competence. Surprisingly, no difference in intrinsic rewards or work engagement was found between occupational groups. This suggests that it is possible for both white-collar and blue-collar workers to gain high levels of intrinsic rewards from their work, emphasising the importance for organisations to enhance intrinsic rewards for all groups of employees.

Whilst sufficient reliability was found for both instruments, this study did not validate the WEP within the South African context as an instrument to measure intrinsic rewards, which was a goal of this research. Having a valid and reliable instrument to measure intrinsic rewards is a key tool in encouraging the increased use of intrinsic rewards for motivation and engagement of employees.

Many organisations are not yet using intrinsic methods to motivate employees (Dewhurst, Guthridge \& Mohr, 2009). This research adds to the growing body of evidence 
suggesting that if organisations offer their employees an environment from which they can source an array of intrinsic rewards, then such organisations may experience the benefits of having engaged employees. Therefore, by creating an environment in which employees can satisfy their own intrinsic needs through working towards the goals of the organisation, organisations can create the optimal solution for both the employees and the employer (Hackman \& Lawler, 1971).

\section{Acknowledgements Competing interests}

The authors declare that they have no financial or personal relationships that may have inappropriately influenced them in conducting the research or writing this article.

\section{Authors' contributions}

S.J. (Nelson Mandela Metropolitan University) completed this research for her Honours treatise in partial fulfilment of her BCom Honours degree in Industrial and Organisational Psychology. R.J.S. (Nelson Mandela Metropolitan University) and M.R. (Nelson Mandela Metropolitan University) were her co-supervisors. S.J. was primarily responsible for the research, including compiling the literature review, conducting the research amongst the retail organisation under study and discussing the results and implications. M.R. and R.J.S. assisted with the data analysis, overall editing and co-authoring of this manuscript.

\section{References}

Allen, R.S., \& Helms, M.M. (2001). Reward practices and organizational performance. Compensation and Benefits Review, 33(4), 74-80. http://dx.doi. org $/ 10.1177 / 08863680122098450$

Amabile, T.M., Hill, K.G., Hennessey, B.A., \& Tighe, E.M. (1994). The Work Preference Inventory: Assessing intrinsic and extrinsic motivational orientations. Journal of Personality and Social Psychology, 66(5), 950-67. http://dx.doi. org/10.1037/0022-3514.66.5.950

Armstrong, M., \& Brown, D. (2009). Strategic rewards: Implementing more effective reward management. London, UK: Kogan Page.

Babbie, E. (2013). The practice of social research. (13th edn.). Ontario, Canada: Cengage Learning.

Bakker, A.B., \& Demerouti, E. (2007). The Job Demands-Resource model: State of the art. Journal of Managerial Psychology, 22(3), 309-328. http://dx.doi. org/10.1108/02683940710733115

Bakker, A.B., \& Demerouti, E. (2009). The crossover of work engagement between working couples: A closer look at the role of empathy. Journal of Managerial Psychology, 24(3), 220-236. http://dx.doi.org/10.1108/02683940910939313

Bakker, A.B., Schaufeli, W.B., Leiter, M.P., \& Taris, T.W. (2008). Work engagement: An emerging concept in occupational health psychology. Work and Stress, 22(3) 187-200. http://dx.doi.org/10.1080/02678370802393649

Bitzer, J., Schrettl, W., \& Scroder, P.J. (2007). Intrinsic motivation in open source software development. Journal of Comparative Economics, 35, 160-169. http:// dx.doi.org/10.1016/j.jce.2006.10.001

Burke, M.M. (2004). Exploring differences in intrinsic motivation based on Keirseyan temperament type. Unpublished doctoral dissertation, California School of Organizational Studies, Alliant International University, San Francisco Bay.

Coetzee, M., \& De Villiers, M.A. (2010). Sources of job stress, work engagement and career orientations of employees in a South African financial institution. SA Business Review, 14(1), 27-57.

Cruz, N.M., Perez, V.M., \& Cantero, C.T. (2009). The influence of employee motivation on knowledge transfer. Journal of Knowledge Management, 13(6), 478-490. http://dx.doi.org/10.1108/13673270910997132

Deci, E.L., \& Ryan, R.M. (1985). Intrinsic motivation and self-determination in human behaviour. New York, NY: Plenum. http://dx.doi.org/10.1007/978-1-4899-2271-7

Deci, E.L., \& Ryan, R.M. (2000). The 'what' and 'why' of goal pursuits: Human needs and the self-determination of behavior. Psychological Inquiry, 2, 227-268. http:// dx.doi.org/10.1207/S15327965PLI1104_01
Dewhurst, M., Guthridge, M., \& Mohr, E. (2009). Motivating people: Getting beyond money. McKinsey Quarterly, November, 1-5. Retrieved January 13, 2014, from http://www.mckinsey.com/insights/organization/motivating_people_getting_ beyond_money

Evenson, R. (2007). Award-winning customer service: 101 ways to guarantee great performance. New York, NY: Amacom.

Family and Work Institute. (2006). Generation and gender in the workplace. Retrieved September 29, 2013, from http://familiesandwork.org/site/research/reports/ genandgender.pdf

Field, L.K., \& Buitendach, J.H. (2011). Happiness, work engagement and organisational commitment of support staff at a tertiary education institution in South Africa. SA Journal of Industrial Psychology, 37(1), 68-77. http://dx.doi.org/10.4102/sajip. v37i1.946

Gallup. (2012). Engagement at work: Its effect on performance continues in tough economic times. Retrieved June 01, 2013, from http://www.gallup.com/ strategicconsulting/161459/engagement-work-effect-performance-continuestough-economic-times.aspx

Gibbons, J. (2006). Employee engagement: A review of current research and its implications. Retrieved June 12, 2013, from http://montrealoffice.wikispaces. com/file/view/Employee+Engagement+-+Conference+Board.pdf

Gravetter, F.J., \& Wallnau L.B. (2009). Statistics for the behavioral sciences. (8th edn.). Belmont, CA: Wadsworth, Cengage Learning.

Hackman, J.R., \& Lawler, E.E. (1971). Employee reactions to job characteristics. Journal of Applied Psychology, 55, 259-286. http://dx.doi.org/10.1037/h0031152

Hair, J.F., Black, W.C., Babin, B.J., \& Anderson, R.E. (2010). Multivariate data analysis. (7th edn.). Upper Saddle River, NJ: Pearson. http://dx.doi.org/10.1016/j. jmva.2009.12.014

Harter, J.K., Schmidt, F.L., \& Hayes, T.L. (2002). Business-unit level relationships between employee satisfaction, employee engagement and business outcomes. Journal of Applied Psychology, 87(2), 268-279. http://dx.doi.org/10.1037/00219010.87.2.268

Harter, J.K., Schmidt, F.L., Killham, E.A., \& Asplund, J.W. (2006). Q12 Meta-analysis Retrieved July 20, 2013, from http://strengths.gallup.com/private/Resources/ Q12Meta-Analysis_Flyer_GEN_08 08_BP.pdf

Herzberg, F. (1966). Work and the nature of man. Cleveland, OH: World Publishing.

Hood, S., Hopson, R.K., \& Frierson, H.T. (2005). The role of culture and cultural Context: A mandate for inclusion, the discovery of truth and understanding in evaluative theory and practice. Charlotte: Information Age Publishing.

Houkes, I. (2002). Work and individual determinants of intrinsic work motivation, emotional exhaustion and turnover intention. Unpublished doctoral dissertation, Department of Health Organisation, Policy and Economics, Maastrich University, Maastricht, The Netherlands. Retrieved August 18, 2013, from http:// publications.maastrichtuniversity. $\mathrm{nl} / \mathrm{en} /$ page/body/record?identifier=oai\%3Ada re\%3A31071

James, J.B., McKechnie, S., \& Swanberg, J. (2011). Predicting employee engagement in an age-diverse retail workforce. Journal of Organizational Behaviour, 32 173-196. http://dx.doi.org/10.1002/job.681

Kahn, W.A. (1990). Psychological conditions of personal engagement and disengagement at work. Academy of Management Journal, 33(4), 692-724. http://dx.doi.org/10.2307/256287

Kenexa. (2012). The world of retail: the 2012 Worktrends report. Retrieved September 15, 2013, from http://www.kenexa.com/getattachment/25e78e27-b280-45d7b3e6-300ddf28d799/How-Employee-Engagement-Can-Help.aspx

Lancaster, L. \& Stillman, D. (2002). When generations collide. New York, NY: Harper Business.

Macey, W.H., \& Schneider, B. (2008). The meaning of employee engagement Industrial and Organizational Psychology, 1(3), 3-30. http://dx.doi.org/10.1111/ j.1754-9434.2007.0002.x

Malhotra, N.K. (2010). Marketing research: An applied orientation. (6th edn.). Upper Saddle River, NJ: Pearson. http://dx.doi.org/10.1108/S1548 6435(2010)0000007010

Marchington, M., \& Wilkinson, A. (2008). Human resource management at work: People management and development. London, UK: Chartered Institute of Personnel and Development.

Markova, G., \& Ford, C. (2011). Is money the panacea? Rewards for knowledge workers. International Journal of Productivity and Performance Management 60(8), 813-823. http://dx.doi.org/10.1108/17410401111182206

Maslach, C., Jackson, S.E., \& Leiter, M. (1996). Maslach Burnout Inventory manual. (3rd ed.). Palo Alto, CA: Consulting Psychologists Press.

Maslach, C., \& Leiter, M.P. (1997). The truth about burnout. San Francisco, CA: Jossey Bass.

Nantha, Y.S. (2013). Intrinsic motivation: How can it play a pivotal role in changing clinician behaviour? Journal of Health Organization and Management, 27(2), 266-272. http://dx.doi.org/10.1108/14777261311321815

Nujjoo, A., \& Meyer, I. (2012). The relative importance of difference types of rewards for employee motivation and commitment in South Africa. SA Journal of Human Resource Management, 10(2), 442-452. http://dx.doi.org/10.4102/sajhrm. v10i2.442

Olivier, A.L., \& Rothmann, S. (2007). Antecedents of work engagement in a multinational oil company. SA Journal of Industrial Psychology, 33(3), 49-56. http://dx.doi.org/10.4102/sajip.v33i3.396

Pink, D.H. (2009). Drive: The surprising truth about what motivates us. New York, NY: The Penguin Group. 
Purcell, J., Kinnie, K., Hutchinson, S., Rayton, B., \& Swart, J. (2003). Understanding the people and performance link: Unlocking the black box. London, UK: Chartered Institute of Personnel and Development.

Rothmann, S., \& Rothmann, S. Jr. (2010). Factors associated with employee engagement in South Africa. SA Journal of Industrial Psychology, 36(2), 1-12. http://dx.doi.org/10.4102/sajip.v36i2.925

Ryan, R.M., Connell, J.P., \& Plant, R.W. (1990). Emotions in nondirected text learning. Learning and Individual Differences, 2(1), 1-17. http://dx.doi.org/10.1016/10416080(90)90014-8

Ryan, R.M., \& Deci, E.L. (2000). Self-determination theory and the facilitation of intrinsic motivation, social development, and well-being. American Psychologist, 55, 68-78. http://dx.doi.org/10.1037/0003-066X.55.1.68

Schaufeli, W., \& Bakker, A. (2003). UWES Utrecht Work Engagement Scale: Preliminary manual (version 1). Retrieved June 11, 2013, from www.arnoldbakker.com/ articles.php

Schaufeli, W., \& Bakker, A. (2004). Towards a model of work engagement. Career Development International, 13(3), 209-223.

Schaufeli, W.B., Bakker, A., \& Salanova, M. (2006). The measurement of work engagement with a short questionnaire. Educational and Psychological Measurement, 66(4), 701-716. http://dx.doi.org/10.1177/0013164405282471

Schaufeli, W.B., Salanova, M., Gonza'lez-Roma, V., \& Bakker, A.B. (2002). The measurement of engagement and burnout: A two sample confirmatory factor analytic approach. Journal of Happiness Studies, 3, 71-92. http://dx.doi. org/10.1023/A:1015630930326

Seligman, M.E.P., \& Csikszentmihalyi, M. (2000). Positive psychology: An introduction American Psychologist, 55(1), 5-14. http://dx.doi.org/10.1037/0003-066X.55.1.5

Shamir, B. (1991). Meaning, self and motivation in organisations. Organisation Studies, 12(3), 405-424. http://dx.doi.org/10.1177/017084069101200304

Shernoff, D.J., Csikszentmihalyi, M., Schneider, M., \& Shernoff, E.S. (2003). Student engagement in high school classrooms from the perspective of Flow Theory. School Psychology Quarterly, 18(2), 158-176. http://dx.doi.org/10.1521/ scpq.18.2.158.21860

Simpson, M. (2009). Predictors of work engagement among medical-surgical registered nurses. Western Journal of Nursing Research, 31(1), 44-65. http:// dx.doi.org/10.1177/0193945908319993

Snelgar, R.J., Renard, M., \& Venter, D. (2013). An empirical study of the reward preferences of South African employees. SA Journal of Human Resource Management, 11(1), 84-97. http://dx.doi.org/10.4102/sajhrm.v11i1.351
Stommel, M. \& Willis, C. (2004). Clinical research: Concepts and principles for advanced practice nurses. Philadelphia, PA: Lippincott Williams \& Wilkins.

Storm, K., \& Rothmann, S. (2003). A psychometric analysis of the Utrecht Work Engagement Scale in the South African police force. SA Journal of Industria Psychology, 29(4), 62-70. http://dx.doi.org/10.4102/sajip.v29i4.129

Stumpf, S.A., Doh, J.P., \& Tymon, W.G. Jr. (2010). The strength of HR practices in India and their effects on employee career success, performance, and potential. Human Resource Management, 49(3), 353-375. http://dx.doi. org $/ 10.1002 / \mathrm{hrm} .20361$

Taylor, S. (2008). People resourcing. (4th edn.). London, UK: Chartered Institute of Personnel and Development.

Thomas, K.W. (2009a). The four intrinsic rewards that drive employee engagement. Ivey Business Journal, 73(6), 1-12. Retrieved June 06, 2013 from www.iveybusinessjournal.com/topics/the-workplace/the-four-intrinsicrewards-that-drive-employee-engagement

Thomas, K.W. (2009b). Technical brief for the Work Engagement Profile: Content, reliability and validity. Mountain View, CA: CPP.

Thomas, K.W. (2009c). Intrinsic motivation at work: What really drives employee engagement. (2nd edn.). San Francisco, CA: Berrett-Koehler Publishers.

Thomas, K.W., Jansen, E., \& Tymon, W.G. Jr. (1997). Navigating in the realm of theory: An empowering view of construct development. Research in Organizational Change and Development, 10, 1-30.

Thomas, K.W., \& Tymon, W.G Jr. (1994). Does empowerment always work: Understanding the role of intrinsic motivation and personal interpretation. Journal of Management Systems, 6(2), 1-13.

Towers Perrin. (2005). Reconnecting with employees: Quantifying the value of engaging your workforce. London, UK: Towers Perrin.

Tsui, A.S., \& Wu, J.B. (2005). The new employment relationship versus the mutual investment approach: Implications for human resources management. Human Resource Management, 44(2), 115-121. http://dx.doi.org/10.1002/ hrm.20052

Whitehead, T., \& Kotze, M. (2003). Career and life balance of professional women: A South African study. SA Journal of Human Resource Management 1(3), 77-84. http://dx.doi.org/10.4102/sajhrm.v1i3.19

Zenger, T.R., \& Lazzarini, S.G. (2004). Compensating for innovation: Do smal firms offer high-powered incentives that lure talent and motivate effort? Managerial and Decision Economics, 25, 329-345. http://dx.doi.org/10.1002/ mde.1194 